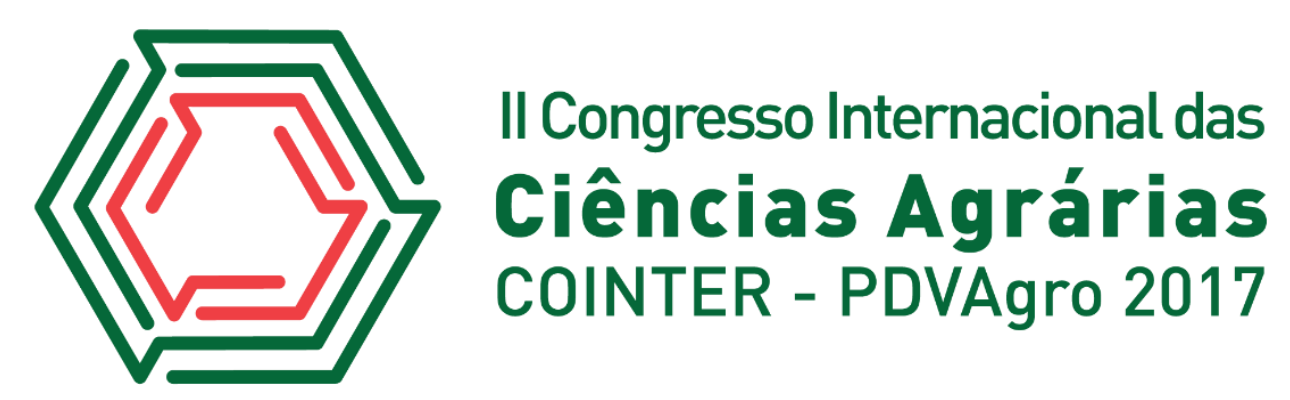

\title{
USO DA FOTOGRAFIA PARTICIPATIVA COMO FERRAMENTA DE APROXIMAÇÃO DE JOVENS COM O CAMPO
}

\author{
Apresentação: Pôster
}

Gisele Silva Oliveira ${ }^{1}$; Márcio José Pereira ${ }^{2}$; Hugo César Peixoto Coutinho ${ }^{3}$

\section{Introdução}

O campo vem perdendo consideravelmente seu contingente populacional durante as últimas décadas. Entre os jovens essa desintegração camponesa se torna maior, pois, com o advento de melhores condições nas cidades urbanizadas, acabam deixando o campo em busca de estudo, de trabalho e condições de vida (RODRIGUES; PERIPOLLI, 2014).

A busca por estratégias que despertem o interesse do jovem pelo campo é de estrema importância na luta contra o êxodo rural, em meio a isso, a fotografia participativa pode ser uma importante ferramenta na construção de um novo significado para o campo, Meirinho (2014) explica que a percepção visual da realidade passa pelo exercício autoral de quem produz a imagem, sendo-a um conjunto de escolhas que refletem o repertório cultural e pessoal de cada indivíduo.

A fotografia participativa, segundo Meirinho (2012), privilegia os jovens enquanto criadores, e não somente receptores das imagens que circulam ao seu redor. A base conceitual é fundamentada nas estratégias da metodologia do photovoice (fotovoz), onde a proposta metodológica parte da utilização da fotografia como ferramenta de base para a ação social e desenvolvimento comunitário.

Desta forma, objetivou-se avaliar o efeito do uso da fotografia participativa na comunidade rural do Oiteiro, município de Vitória de Santo Antão - Pernambuco, como estratégia de aproximação do jovem com o campo.

\footnotetext{
${ }^{1}$ Graduanda em Bacharelado em Agronomia, Instituto Federal de Educação, Ciência e Tecnologia de Pernambuco Campus Vitória, Oliveira_gs@outlook.com

${ }^{2}$ Graduando em Bacharelado em Agronomia, Instituto Federal de Educação, Ciência e Tecnologia de Pernambuco Campus Vitória, marciojose058@gmail.com

${ }^{3}$ Mestre em Gestão do Desenvolvimento Local Sustentável, Instituto Federal de Educação, Ciência e Tecnologia de Pernambuco - Campus Vitória, hugo.peixoto@vitoria.ifpe.edu.br
} 


\section{Fundamentação Teórica}

A fotografia participativa para Valdivia (2013) é uma metodologia que encontra suas principais influências sobre as teorias de comunicação participativa, abordagem de pesquisa-ação participativa e a pedagogia dialógico crítico de Paulo Freire. É amplamente conhecido como photovoice. O termo refere-se à capacidade que a fotografia tem de dar voz às pessoas que comumente são esquecidas, através dela é possível que seu ponto de vista seja exposto e defendido por eles próprios antes de outros atores da sociedade.

Para Pizarro (2012), tirar uma foto é uma escolha para capturar um momento ou o que ele representa, para muitas pessoas - especialmente para adolescentes, sempre com inseguranças e duvidas específicas para seus idade - pode ser mais difícil comunicar o que significam ou se expressar através de palavras orais ou escritas. A fotografia permite transmitir uma mensagem de forma simples e direta, facilitando a comunicação de idéias ou opiniões para aqueles que normalmente eles não estão acostumados a expressá-los da maneira tradicional.

Os estudos de Meirinho (2014) corroboram com as afirmações dos autores anteriormente citados e afirma ainda que a fotografia pode ser usada como ferramenta que amplia a forma de expressão dos jovens, revelando muito sobre suas perspectivas individuais, refletindo o mundo ao seu redor, além de possibilitar que adolescentes representem visualmente os seus interesses e as angústias nessa etapa da vida merecedora de interpretações que valorizam instrumentos linguísticos mais criativos e colaborativos.

\section{Metodologia}

A pesquisa tem caráter qualitativo do tipo pesquisa-ação, foi desenvolvida nos meses de maio e junho de 2016 na comunidade do Oiteiro, localizada na zona rural de Vitória de santo antão, Pernambuco. A metodologia utilizada foi baseada no photovoice, onde os participantes são estimulados a refletir a cerca de seu contexto social através do material fotográfico por eles produzido.

O critério de escolha dos participantes foi ser agricultor ou agricultora ou filho de agricultores da comunidade, além disso, não era necessário que os jovens possuíssem câmeras sofisticadas. Participaram jovens de idades entre 16 e 24 anos, onde $90 \%$ eram do sexo feminino e apenas $10 \%$ do sexo masculino e com grau de escolaridade entre o ensino fundamental I e ensino 
médio completo.

Os encontros aconteceram no centro de convivência da comunidade, foram realizadas dinâmicas de apresentação onde cada participante deveria desenhar com o máximo de detalhes uma foto de um momento importante de sua vida, exibir para os outros participantes e, além de contar um pouco da história por trás do desenho, falar quais dificuldades tiveram na hora de retratar essa foto, após isso, foram distribuídos jornais para que cada um escolhesse uma foto e em seguida, sem mostrar aos outros participantes, foi feita a descrição da imagem escolhida.

Nas reuniões também ocorreram oficinas teóricas para abordar a história e conceitos a respeito da fotografia, os tipos de câmera, questões a respeito do foco, enquadramento, composição, flash, luz, distância focal, controle do obturador, armazenamento de imagem e recursos das maquinas fotográficas.

Além disso, foram realizadas expedições fotográficas pela comunidade, onde os participantes utilizaram celulares e câmeras digitais. Durante as expedições foram estimulados debates a respeito da comunidade, dos problemas e das dificuldades que os jovens enfrentavam no dia a dia. Ao final dos encontros, as melhores fotos foram selecionadas para serem expostas no centro de convivência do Oiteiro para os demais moradores da comunidade.

\section{Resultados e Discussões}

Ao produzir as fotografias, o jovem é estimulado em todos os sentidos, ele aprecia a paisagem local, percebe a diversidade de significados que cada elemento da comunidade trás, estimula a sensibilidade, a imaginação e o pensamento critico, dessa forma, o contato com a comunidade de uma maneira não convencional incentiva uma maior interação entre o jovem e o campo, despertando um maior sentimento de pertença.

A fotografia possibilitou uma maior confiança entre os jovens para construir seus argumentos, eles reconhecem que a fotografia pode ser um meio de reivindicar melhorias para a comunidade, isso se torna importante para a construção de um ser crítico, favorecendo que eles busquem soluções para a comunidade e não sinta a necessidade sair dela para encontrar melhores condições de vida.

Os encontros resultaram em duas oficinas teóricas, duas expedições fotográficas e uma exposição na comunidade. Nas primeiras reuniões os participantes sentiram mais dificuldade de 
interagir com os outros integrantes, porém as dinâmicas iniciais foram de fundamental importância para promover a comunicação entre os jovens, o compartilhamento de suas histórias de vida e suas perspectivas futuras.

Nas oficinas teóricas buscou-se relacionar o conteúdo visto com as paisagens locais, para que os participantes entendessem com mais clareza os aspectos técnicos e assim aplicá-los com mais eficiência, isso fez uma grande diferença, pois as duvidas que surgiram no momento da prática estavam mais relacionadas a como aprimorar a técnica aprendida nos encontros.

Nas expedições fotográficas houve a troca de equipamentos entre os participantes e notouse um maior interesse pela paisagem natural, composta principalmente pelas áreas de cultivo do Oiteiro, também foram registradas imagens dos trabalhadores rurais realizando suas atividades diárias, além de retratar a vida na vila, registrando momentos característicos da zona rural, como a conversa na calçada, a brincadeira das crianças, os jardins, o trabalho e a volta para casa, com isso, foram produzidas 505 fotos.

Foto 1: Expedições Fotográficas. Fonte: Própria

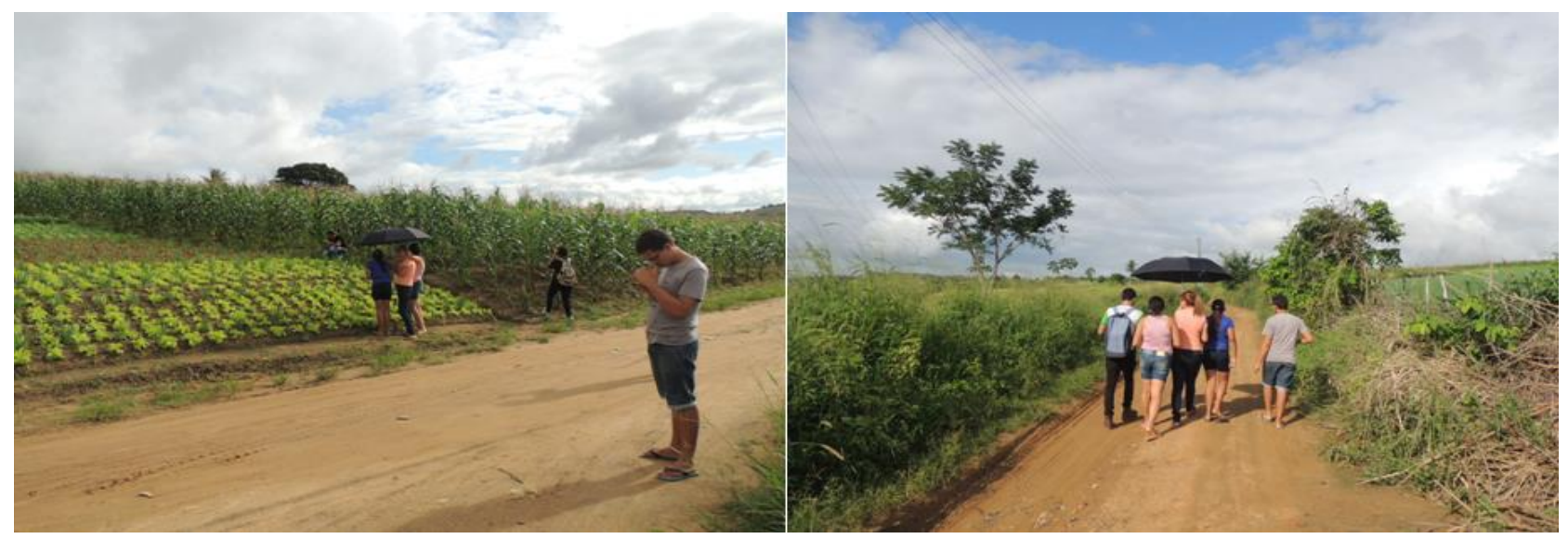

A Exposição no Centro de Convivência do Oiteiro contou com 45 fotos, que teve como critério para seleção a qualidade da luz, o foco, e a composição da imagem, os participantes atribuíram nota de 0 a 5 e as que obtiveram maiores notas foram selecionadas. Durante a exposição, os moradores manifestaram orgulho de ver a comunidade retratada pelos olhos dos jovens e alguns deles demonstraram o interesse de aprofundar seus conhecimentos em fotografia para poder retratar com mais fidelidade toda a comunidade.

Todas as fotografias foram disponibilizadas em DVD para a associação de moradores do Oiteiro, que estava elaborando um memorial da comunidade. Praticamente não ouve evasão entre os participantes, apenas uma pessoa desistiu dos encontros. Por iniciativa dos participantes foi 
criado um grupo com o nome "retratos do campo" em uma rede social de troca de mensagens diretas, onde há a troca de noticias em geral, além das fotografias da comunidade.

\section{Conclusões}

O uso da fotografia participativa foi de extrema importância para promover a aproximação do jovem com o campo, foi possível promover um novo olhar sobre a comunidade, não só para os que participaram dos encontros, mas também para os seus familiares, amigos e pessoas mais próximas, além disso, possibilitou um novo jeito desses jovens se expressarem a respeito de suas preocupações e anseios, porém, assim como Meirinho (2014) afirma, é preciso de um tempo maior de execução dos encontros e discussões mais intensas para poder promover mudanças significativas na comunidade.

\section{Referências}

MEIRINHO, D. A fotografia participativa como ferramenta de expressão e representação social. Foto-ensaio do Projecto "Olhares em Foco". Cadernos de Arte e Antropologia, [S.1.], v. 1, n. 1, p. 77-81, 2012.

MEIRINHO, D. Construção de significados visuais: A participação de jovens a partir da fotografia participativa. Disponível em: <http://www.opj.ics.ul.pt/index.php/fevereiro-2014>. Acesso em: 22 set. 2017.

PIZARRO, C. F. V. Comunícalo con imágenes: la metodología de la fotografía participativa como herramienta para promover identidad local y prevenir conductas de riesgo. La experiencia del proyecto Nuestra Mirada - Callao 2009. 2012. 160 p. Dissertação (Bacharel em Comunicação para o Desenvolvimento)- Pontificia Universidad Católica Del Perú, Lima, 2012.

RODRIGUES, P.S.; PERIPOLLI, O. J. O êxodo rural entre os jovens camponeses: o desafio colocado à escola. Revista Eventos Pedagógicos, [S.1.], v. 5, n. 2, p. 291-300, jul. 2014. Disponível em: $\quad<$ http://sinop.unemat.br/projetos/revista/index.php/eventos/article/viewFile/1505/1117>. Acesso em: 23 set. 2017.

VALDIVIA, C. La imagen es tu voz: la fotografia participativa como herramienta de cambio social. Canalé, Peru, n.5, p. 6-16, 2013. 